\title{
Acquired Hypogonadotropic Hypogonadism
}

National Cancer Institute

\section{Source}

National Cancer Institute. Acquired Hypogonadotropic Hypogonadism. NCI Thesaurus.

Code C120369.

Hypogonadotropic hypogonadism, the cause of which is not present from birth. 